\title{
Julio Ruiz Berrio. Camiños transitados xuntos
}

Julio Ruiz Berrio faleceu 09 de outubro de 2013, no medio da sorpresa de cantos 0 coñeciamos; tíñase gañada a admiración e o recoñecemento da comunidade internacional da Historia da Educación, e de boa parta doutras comunidades científicas que 0 trataron (Historia, Pedagoxía, Socioloxía, etc).

A min invadíronme tamén eses sentimentos, como membro desa comunidade, e como discípulo directo do profesor. Fun deses privilexiados que puiden disfrutar do seu fondo saber, bonhomía e inquedanzas intelectuais diversas, e comprobar ademais a súa elevada categoría profesional, humana e moral. A miña sorpresa foi maiúscula pois sempre conservei del a mesma imaxe de mediana idade; con achaques de saúde, mais disimulados polo seu carácter optimista, alegre e bonachón.

Certo que hai tempo que non nos viamos, e as últimas novas redúcense a referencias de cando preguntaba por el. De cando en vez a Antón, especialmente despois dos Coloquios aos que faltei ultimamente, celebrados en Burgo de Osma e Cádiz. Tiven ocasión de falar de Julio máis detidamente con Sara, cando nos coñecemos en Berlanga. Por ela mandeille unha aperta e un exemplar do traballo que eu viña de publicar sobre Alfonso García Rojo. Con moita satisfacción coñecín a unha discípula da nova xeración, e intercambiamos durante longo tempo ideas sobre os cadernos de rotación, por ser ela unha experta e eu alguén que retornaba á historiografía, analizando as xoias que os fillos de Alfonso e de Rosa Pons deixaban ao meu coidado. Recibín de Julio, a través dunha das súas novas discípulas, as ensinanzas mínimas para interpretar aqueles cadernos das nenas de Parada de Sil.

Estaba eu cociñando a biografía de Rosa Pons e a segunda edición do meu primeiro libro, que non cheguei a mandarllos, esperando a velo persoalmente nalgún encontro. Certo que a historia non foi xusta con nós, pois pasaron anos sen termos os Encontros Ibéricos, nos que abofé teriamos coincidido, e tampouco chegaron ao seu fin as teses de historia que dirixo, das que sen dúbida lle correspondía presidir o tribunal.

Non sendo a historia favorecedora de encontros recentes co meu principal mestre, tamén teño que recoñecer certa infidelidade, ao non ter continuidade na docencia e investigación histórica, e tocar outras pólas da vida universitaria, nas que me deixei aconsellar por outros mestres. A miña dedicación á educación social, á educación para a paz e á política universitaria absorbéronme moito tempo nas últimas décadas.

Podo resumir a miña relación de mestre-discípulo con Julio Ruiz Berrio na etapa de 15 anos que van desde o comezo da miña tese ata o Coloquio de Granada en 1996, pois estiven un tempo sen participar noutras edicións. 0 maxisterio do meu director de tese tivo 
unha dimensión académica que se foi esvaíndo desde esa data, e unha dimensión científica e humana que chega ata hoxe e permanecerá despois da súa morte. Beber nas súas publicacións e lembrar as súas cualidades humanas van ser recursos necesarios durante moito tempo, para ser mellores universitarios e facer unha boa historia da educación, como deixou dito Uxío na mensaxe do día de loito, porque "apreciaba o traballo ben feito, a investigación seria e rotunda, a enerxía para saber e descubrir, e aí era cercano."

En 1982 dirixiu a tese doutra intermediaria nas miñas relacións co mestre, Mercedes Suárez Pazos, investigadora que se achega coma min á historia da educación de forma intermitente, pois a concentración parcelaria das Ciencias da Educación situouna na Didáctica, aínda que sen perder a perspectiva sociohistórica en case todo o que fai. Convencido por Mercedes e Herminio trasladeime a Madrid para cambiar a miña liña de investigación en Pedagoxía Experimental, orientada por Gonzalo Vázquez, por unha liña de historia social da educación, que eles cultivaban con mestría, da man de Julio Ruiz Berrio. Os meus mestres na Universidade galega encamiñábanme pola ruta axeitada para chegar a ser un doutor que crese no que facía.

Os outros dous mestres que teño en Galicia, Antón e Narciso, traballaban con Escolano, aínda que uns e outros remabamos na mesma dirección. Julio e Agustín foron e son os dous grandes referentes para os historiadores da educación en Galicia, aos que se foron sumando outros mais novos, que non nomeo para non cometer ningunha inxustiza. Cecais non sexa inxusto destacar a Aida Terrón, responsable da extensión desta nova historia da educación cara terras asturianas, onde foron moi acolledores coas visitas dos discípulos galegos de Julio, cando el estaba destinado alí en Oviedo. $O$ grupo galego sempre estivo moi unido dentro da SEDHE, en relación cordiais cos historiadores/ as doutras comunidades, nese bo clima xeral existente, e teño unha lembranza especial das amigas e amigos de Asturias, por telos coñecido nas miñas viaxes para falar da tese e recibir sempre esa boa acollida. Nalgún Congreso en que coincidimos no xantar con Aurea Adao e outros amigos portugueses, falamos de maneira informal e humorística da creación dunha sección do noroeste. Era un grupo cunha diversidade moi enriquecedora.

Naquela viaxe a Madrid, en 1981, co respecto que impuña aquela Facultade (esperando pola nosa entrevista puiden ver nas portas dos despachos nomes de profesores que coñecía polos libros manexados na carreira (Galino, Lerena, Rodríguez de Castro, Miguel Santos Guerra...), e co medo de non encontrar director de tese -pois jfaltaríanlle discípulos naquelas terras!- arrancou a miña aventura pola historia da educación republicana sen que me faltase a orientación, o apoio, o consello oportuno, a motivación, a amizade, o alento, a dirección científica e a lección permanente de respecto polas ideas, enfoques e opinións.

Uns minutos no seu despacho e xa remataron as miñas dúbidas. A súa xenerosidade fíxome estar confiado desde o primeiro momento de que contaba coa súa dirección e que a asumía coa seriedade que o caracterizaba.

A miña pretensión de traballar na historia local e nunha etapa que aínda estaba "viva" -tan distante daquel principio do XIX, no que Julio era un gran mestre- podían ser un atranco. A meu favor contaba os avais de Herminio e Mercedes, que nesas datas estaban 
a rematar as súas teses baixo a dirección do mesmo mestre, así como o feito de que se estaba a converter nun dos mais firmes defensores desta nova liña de estudo da historia local, e por suposto nun dos grandes valedores da educación renovadora, pública e laica. A súa biografía de Pablo Montesino ou a mais recente edición da obra de Posada, son evidencia da súa aposta por este modelo educativo, intención que deixou clara no seu clásico estudo sobre Política Escolar de España en el Siglo XIX (1808-1833), publicado en 1970.

A miña proposta ía entrar claramente nesa liña, e servíame de referente o propio traballo de Herminio, pola significación de Luzuriaga no deseño da escola pública republicana. Con estes referentes, a miña proposta pretendía contribuír á análise dos feitos educativos desde a posición das clases populares e desde a perspectiva dos intelectuais e docentes mais dinámicos, como foron os mestres da ATEO, e os ideólogos republicanos, marxistas, galeguistas e renovadores en xeral, que en Ourense non eran menos que noutras partes

Volvín de Madrid co convencemento de que contaba co mellor director para ese proxecto. Volvín co compromiso de non decepcionar ao mestre e a moitos mestres que seguín encontrando no camiño, protagonistas dos anos vinte, trinta e corenta. Volvín coas baterías cargadas, con ilusión e con gañas de recuperar a memoria da escola pública en Ourense. Julio faría referencia a traballos meus na análise da escola pública incluída na Historia de la educación en la España contemporánea: diez años de investigación, editada por el mesmo en colaboración con Tiana e Guereña en 1994.

Non fun un discípulo ortodoxo, pois tiña o meu proxecto de tese, e escoitei pouco as primeiras indicacións do mestre. Foi Julio quen se decatou dos meus intereses e soubo virar as súas orientacións motivadoras cara ese lado. As súas primeiras indicacións foron que traballase sobre o primeiro terzo do século XX. Non abondaba coa República, que era un período moi curto, e ademais a distancia temporal non era suficiente para ter un camiño fácil. Tampouco fun desleal, pero fun tentando convencelo de que a República daba moito de si, Ourense era unha caixa de sorpresas e o camiño iríase despexando. $O$ inconveniente da proximidade no tempo pronto o puiden comprobar no acceso a algúns arquivos, pero tiña a contrapartida de traballar con ricos testemuños orais e coa recuperación de arquivos privados. Era o momento de recuperalos ou perdelos para sempre.

Esta fortaleza e a riqueza da información obtida fórono convencendo de que o traballo tería entidade e relevancia limitándose ao período republicano. Tardei en comentarllo ata que estiven moi seguro. Inicialmente recollín datos do primeiro terzo de século non querendo que a miña teima se convertese en deslealdade ou mesmo en falta de rigor científico e metodolóxico.

A Casa do Pobo, a axitación agraria de Basilio Álvarez, a formación de pedagogos galegos na Escola de Estudos Superiores do Maxisterio, as escolas laicas e de emigrantes, as do Ave María, as Irmandades da Fala e a Xeración Nós, a asemblea da asociación de mestres no Carballiño, eran historias relevantes e non eran procesos alleos ao que acontecería na IIํㅡㄹ República. Outros feitos e procesos dese principio de século arquivábaos na "carpeta B", por se era preciso volver a eles. 


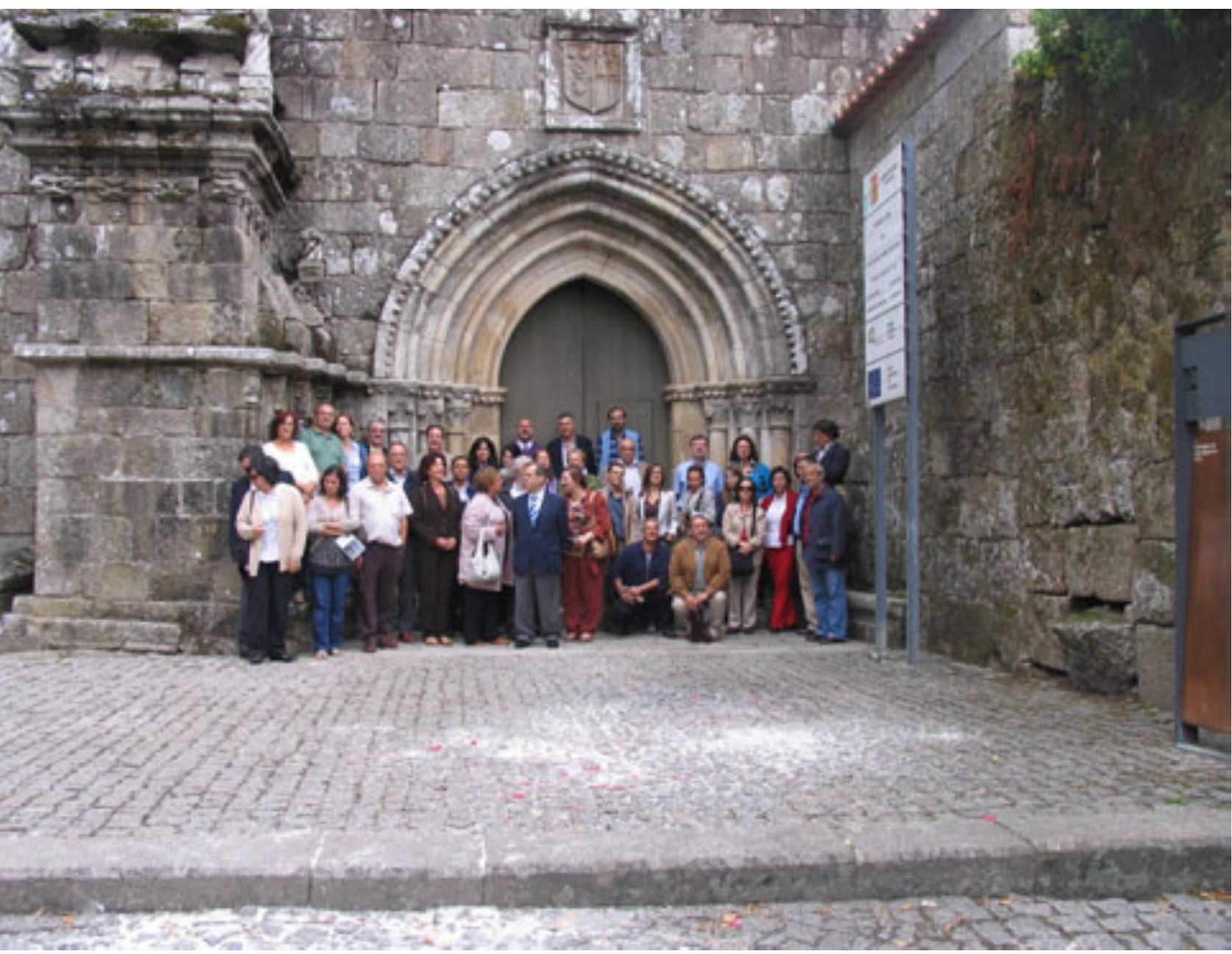

Encontro ibérico.

Así foi madurando o traballo. Ata que se inventou o correo electrónico, eran frecuentes as cartas, chamadas de teléfono -o seu era un dos números que tiña memorizados, e contaba coa confianza de chamar desde calquera parte e en calquera día que se encontrase na súa casa en Madrid- ou as postais polo natal e ano novo (cunha redacción laica tanto na ida como na volta). Nos coloquios, nas viaxes a Santiago con motivo de tribunais de teses, ou nas miñas visitas a Oviedo sempre había tempo para recibir as oportunas indicacións para levar o traballo a bo fin. Sempre arroupado e debidamente orientado. Foi nun deses encontros na sala de visita do Hotel Compostela cando convencín a Julio para delimitar o meu traballo no período republicano. Levaba xa un amplo capítulo sobre a reacción clerical contra a escola republicana, e algún exemplar da revista Escuela 
del Trabajo. A descuberta deste material produciulle tanta emoción como me tiña producido a min. Descubrimos que Ourense contribuíu de maneira insospeitada a fortalecer o modelo de educación republicana. Quedou convencido, e ademais, coma sempre, respectou a miña opción, despois de escoitar os argumentos e adaptar as súas indicacións na liña que eu as demandaba. Se lle quedou algunha dúbida, disiparíase o día da lectura cando tres mestres do Plano Profesional decidiron acompañarme en Santiago nese acto. Era, como dixo Herminio, o primeiro día da primavera de 1987. O meu traballo sobre a educación republicana en Ourense era máis que unha investigación. Era recuperar a autoestima dunha xeración vilipendiada pola reacción franquista e clerical. Julio sabía ver esa dimensión da actividade investigadora, máis emocional que científica, pero sen a cal non tería sentido a descuberta científica.

Foi un mestre e tamén un amigo. Un par de anos máis tarde sería tamén o presidente do tribunal da miña oposición a Titular de Universidade. Alguén viu mal que un catedrático de Historia da Educación presidise un tribunal de Teoría da Educación, pero como el me ensinou, esa fronteira, igual que outras, é artificial. Con ela non se pretende mellorar o proceso de produción de coñecemento, senón resolver problemas burocráticos da Universidade.

A nosa relación continuou sendo estreita ata mediados os anos noventa. Logo foise perdendo pola miña implicación en política universitaria, que me apartou temporalmente da investigación histórica. Encontrámonos en algúns congresos en Portugal, onde tiñamos ocasión de falar con máis tranquilidade que noutros foros, pois el asistía con menos compromisos protocolarios, e ademais pedíame que lle traducise moitas cousas que non entendía: no Porto en 1988 era un dos poñentes convidados a un Congreso que tivo lugar na ESE do Instituto Politécnico; en Lisboa en 1993, con motivo do Congreso Internacional de Historia da Educación, e o ano seguinte acompañounos nos Cursos de Verán de Chaves para analizar a historia das reformas educativas españolas e portuguesas. Foi alí, en Chaves, a mediados dos noventa, cando tivemos as nosas máis longas conversas. Américo e os amigos e amigas de Chaves facían aquel lugar aínda mais acolledor do que é. En Granada, dous anos despois, xa lembro que me preguntou como me ía na política universitaria (era eu Decano de Humanidades, responsable da posta en marcha das novas titulacións de educación), sabedor de que a miña presenza nos foros da Historia da Educación quedaba en segundo plano.

Nalgún Encontro Ibérico volvemos coincidir, particularmente no que me tocou organizar en Allariz, pero a nosa colaboración nesa altura xa non tiña a intensidade dos anos oitenta. De feito seguín desde a distancia o seu extraordinario labor na Sociedad Española para el Estudio del Patrimonio Histórico-Educativo (SEPHE), e lémbrome das ensinanzas do mestre cando entro no humilde Museo que temos na Facultade de Ciencias da Educación, pero non cheguei a integrarme na asociación nin a participar en actividades da mesma. Galicia estaba ben representada por Uxío, como especialista en Cossío, o artífice da tradición museística na educación, e por Vicente, daquela asesor do MUPEGA. Eu tal vez poda honrar a súa memoria custodiando o material que temos no Museo e poñéndoo ao servizo da construción de novas historias da educación. 
Non participei nese ultimo gran proxecto de Julio, pero o que aprendín con el naqueles anos oitenta e noventa ségueme resultando útil para retomar traballos históricos, como as biografías de mestres republicanos de Ourense. Deixamos de ter o consello oportuno do mestre para mellorar calquera investigación que abordemos, pero sempre podemos recorrer ao seu legado intelectual para tratar de ser bos universitarios, boas persoas e facer boa historia da educación, desde a colaboración e a suma de esforzos. De todo isto, Julio Ruiz Berrio foi un modelo que queda para sempre na nosa memoria.

Xosé Manuel CID

Universidade de Vigo 